\title{
INFLUÊNCIAS DA ASSOCIAÇÃO ENTRE DANOS MECÂNICOS E PATÓGENOS NO DESEMPENHO DAS SEMENTES DE MILHO (Zea mays L.)
}

\section{CARLOS MOURE CICERO \\ Engenheiro Agrônomo}

Orientador: Prof. Dr. Walter Rodrigues da Silva

Dissertação apresentada à Escola Superior de Agricultura "Luiz de Queiroz", Universidade de São Paulo, para a obtenção do título de Mestre em Agronomia, Área de Concentração:

Fitotecnia.

PIRACICABA

Estado de São Paulo - Brasil

Maio -2000 
Dados Internacionais de Catalogação na Publicação (CIP) DIVISĀO DE BIBLIOTECA E DOCUMENTAÇÃO - Campus "Luiz de Oueiroz"/USP

Cicero, Carlos Moure

Influências da associação entre danos mecânicos e patógenos no desempenho das sementes de milho (Zea mays L.) / Carlos Moure Cicero. -- Piracicaba, 2000.

39 p. : il.

Dissertação (mestrado) - - Escola Superior de Agricultura Luiz de Queiroz, 2000. Bibliografia.

1. Beneficiamento 2. Dano Mecânico 3. Microrganismo patogênico 4. Qualidade fisiológica 5. Semente de milho I. Título

CDD 633.15 
Aos meus amores,

minha esposa Lydia, minhas filhas Mariana e Gabriela

Dedico.

Aos meus queridos pais, José e Esther

Ofereço. 


\section{AGRADECIMENTOS}

Aos meus queridos pais, José e Esther, por tudo.

À minha esposa Lydia e às minhas filhas Mariana e Gabriela, os grandes amores de minha vida (fizeram o Mestrado junto comigo).

À Universidade de Taubaté, através do Departamento de Ciências Agrárias, em especial à sua Administração, e à Escola Superior de Agricultura "Luiz de Queiroz", através do Departamento de Produção Vegetal, em especial aos seus professores, pela oportunidade da realização do Curso.

Ao Professor Dr. Walter Rodrigues da Silva, pelo apoio, participação e orientação, fundamentais em todas as atividades.

Ao Professor Dr. Sílvio Moure Cicero, irmão e espelho.

Aos amigos que compartilhei parte de minha vida, desde o início do Curso e em especial para João, Omar, Oscar, Cristina, Angélica, Marcelo, Daniel, Odair e llze. 


\section{SUMÁRIO}

LISTA DE TABELAS.............................................................. v v

RESUMO...................................................................................... vi

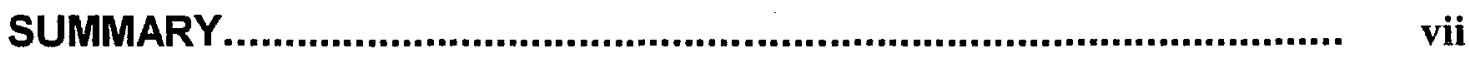

1 INTRODUÇÃO............................................................................ 1

2 REVISÃO DE LITERATURA......................................................... 2

3 MATERIAL E MÉTODOS.............................................................. 8

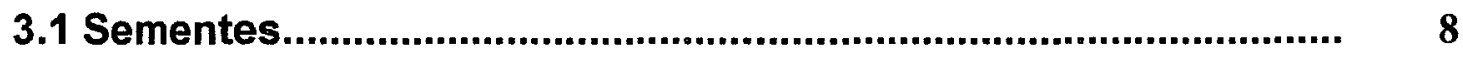

3.2 Obtenção dos tratamentos..................................................... 8

3.3 Determinações...................................................................... 10

3.3.1 Caracterização do lote original............................................. 10

3.3.2 Avaliações dos tratamentos................................................. 12

3.4 Delineamento experimental e análise estatística....................... 14

4 RESULTADOS E DISCUSSÃO.................................................. 16

4.1 Caracterização do lote original............................................... 16

4.2 Avaliações dos tratamentos.................................................. 17

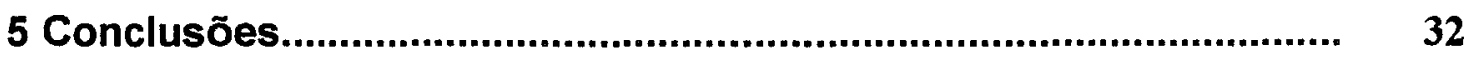

REFERÊNCIAS BIBLIOGRÁFICAS............................................ 33 


\section{LISTA DE TABELAS}

1a Esquema da análise estatística aplicada, por experimento, nos Página dados dos testes fisiológicos realizados na avaliação dos tratamentos.

1b Esquema da análise estatística aplicada, por experimento, nos dados dos testes da densidade ponderada de infecção realizado na avaliação dos tratamentos.

2 Dados da qualidade das sementes (lote original) obtidos anteriormente à aplicação dos tratamentos.

3 Determinação do grau de umidade: dados (\%) obtidos após a aplicação dos tratamentos.

4 Teste de dano mecânico: dados (\%) da incidência de fungos obtidos após a aplicação dos tratamentos.

5 Teste de sanidade: dados (\%) da incidência de fungos obtidos após a aplicação dos tratamentos.

6 Densidade ponderada de infecção: dados (\%) obtidos após a aplicação dos tratamentos..

7 Teste de germinação: dados (\%) obtidos após a aplicação dos tratamentos.

8 Teste de tetrazólio: dados (\%) de viabilidade obtidos após a aplicação dos tratamentos.

9 Teste de envelhecimento artificial: dados (\%) obtidos após a aplicação dos tratamentos.

10 Teste de frio: dados (\%) obtidos após a aplicação dos tratamentos.

11 Teste de comprimento de plântula: dados $(\mathrm{mm})$ obtidos após a aplicação dos tratamentos.

12 Teste de emergência das plântulas: dados (\%) obtidos após aplicação dos tratamentos. 


\title{
INFLUÊNCIAS DA ASSOCIAÇÃO ENTRE DANOS \\ MECÂNICOS E PATÓGENOS NO DESEMPENHO DAS SEMENTES DE \\ MILHO (Zea mays L.)
}

\author{
Autor: CARLOS MOURE CICERO \\ Orientador: WALTER RODRIGUES DA SILVA
}

\section{RESUMO}

As danificações provocadas nas sementes, por operações mecanizadas realizadas durante a produção, podem atuar negativamente na qualidade do material obtido; esta redução qualitativa, segundo a literatura específica, pode ser agravada quando a injúria interage com microrganismos presentes na superfície das sementes ou no solo, por ocasião da semeadura. Desta forma o presente trabalho, realizando inoculações de patógenos e injúrias nas regiões da calota endospermática, do ápice do escutelo e da camada negra em sementes de milho, objetivou verificar as relações existentes entre as danificações mecânicas, a presença de microrganismos e o desempenho das sementes. Após a realização de testes sanitários e fisiológicos, foi concluído que as danificações, particularmente quando Aspergillus sp. e Fusarium moniliforme acham-se presentes nas sementes, promovem prejuízos qualitativos progressivos à medida que se aproximam do embrião; quando comparadas entre $\mathrm{si}$, as interferências negativas de Aspergillus sp. e de Fusarium moniliforme são mais evidentes do que as de Penicillium sp. 


\title{
INFLUENCES OF THE RELATIONSHIP BETWEEN MECHANICAL DAMAGES AND PATHOGENS IN THE PERFORMANCE OF CORN SEEDS
}

(Zea mays L.)

\author{
Author: CARLOS MOURE CICERO \\ Adviser: WALTER RODRIGUES DA SILVA
}

\section{SUMMARY}

The damages provoked by seeds due to mechanized operations performed along production can negatively affect the quality of the material reached; according to specific literature, this qualitative reduction can be aggravated when the injury interacts with the microorganisms found in the seed surface or in the soil at seeding. Thus, by performing pathogen and injury inoculations in the region of the endosperm cap, top scutellum and black layer of corn seeds the aim of this paper was to verify the existing relationship between the mechanical damages, the presence of microorganisms and seed performance. After sanitary and physiological tests were carried out one concluded that the damages, particularly when Aspergillus sp. and Fusarium moniliforme were found in the seeds, promote progressive qualitative losses as they approach the embryo; in comparison with one another the negative interference of Aspergillus sp. and Fusarium moniliforme is more evident than those of the Penicillium sp. 


\section{INTRODUÇÃO}

A necessidade de redução das danificações mecânicas, surgidas nas etapas de produção das sementes de milho, tem justificado a adoção de tecnologias especificamente voltadas a essa finalidade. Contudo, apesar das possíveis amenizaçōes em número e intensidade, as injúrias não podem ser totalmente evitadas em decorrência do uso imprescindível de máquinas, particularmente, durante a debulha e o beneficiamento.

A literatura sugere que as sementes de milho transportem vários patógenos que, por sua vez, podem utilizar as vias abertas pelos danos mecânicos para infectar as sementes e, desta forma, afetar negativamente o seu desempenho. Contudo, esta possibilidade, apesar de freqüentemente referida, carece de pesquisas que alicercem, adequadamente, o entendimento do fenômeno.

O objetivo do presente trabalho foi o de estudar, em sementes de milho, as relações existentes entre os danos mecânicos, a presença de microrganismos e o desempenho fisiológico. 


\section{REVISÃO DE LITERATURA}

O milho é cultivado em regiões com características ambientais variáveis. Em vista disso, o grau de incidência e a importância econômica de determinado patógeno são alterados, especialmente, entre anos agrícolas e regiões de cultivo. Um dos veículos potencialmente eficientes para a disseminação de microrganismos é a semente que, com a comercialização, pode transportar e introduzir patógenos nos campos de produção.

$O$ ataque de fungos às sementes pode determinar a ocorrência de várias doenças (Neergaard, 1979) como, por exemplo, o aborto, onde os órgãos florais são substituídos por frutificações dos fungos causadores de carvões e esporões. A podridão de sementes, decorrente da ação de espécies fúngicas incluídas nos gêneros Fusarium, Aspergillus e Penicillium, pode ocorrer no campo, no armazenamento ou no solo, por ocasião da semeadura e emergência. A alteração na cor, além de poder indicar a presença de patógenos, afeta negativamente o valor comercial do produto; em milho, a presença de Fusarium moniliforme pode gerar coloração rosa nas sementes. Os produtos metabólicos dos microrganismos, além de afetarem as sementes, podem ter efeitos tóxicos quando presentes na alimentação.

Segundo Neergaard (1979), na podridão de Fusarium encontram-se associados o Fusarium moniliforme e o Fusarium graminearum. É uma doença de final de ciclo, manifestando-se no colmo e secando a planta prematuramente. As raízes e a parte basal do colmo podem apresentar lesões, que evoluem para podridões capazes de enfraquecer os internódios e promover o tombamento da planta por ocasião de ventos fortes. Nas espigas, o patógeno provoca a 
podridão das sementes, através do crescimento de micélio cotonoso com esporos, promovendo o surgimento de colorações variáveis de rosa a marromavermelhada.

Conforme Neergaard (1979), as sementes podem ser tanto veículos como vítimas de doenças e de desordens conseqüentes de fatores bióticos e ambientais, capazes de comprometer a performance das culturas. Desta forma, ressalta-se a importância dos patógenos, transmitidos por sementes, por suas conseqüências epidemiológicas e decorrentes riscos de introduções em áreas isentas de sua presença. Neste sentido, em diversas culturas, a qualidade fisiológica das sementes pode ser afetada pela presença de agentes causadores de doenças nas sementes que, por sua vez, podem promover a disseminação do problema em novas áreas semeadas (Neergaard, 1979; Dhingra et al.,1980; Filgueiras, 1981; Lucca Filho, 1985).

A análise de sanidade, através da identificação dos microrganismos transportados pelas sementes, pode servir como referencial para a definição de procedimentos destinados a atenuar a ação negativa dos patógenos sobre a qualidade fisiológica do lote (Schwartz, 1980; Richardson, 1981; Pereira, 1984; Tanaka \& Machado, 1985).

A perda da qualidade das sementes pode ser induzida direta ou indiretamente pela danificação mecânica (Fagundes et al., 1972; Brass \& Marley, 1973). Em decorrência da existência de diversos tipos de danificações, o termo dano mecânico necessita ser devidamente definido; assim, Bunch (1960), Goodsell (1964), Fagundes et al. (1972) e Maciel (1977) definiram dano mecânico como sendo a injúria causada por agentes físicos durante o manejo das sementes, nas formas de quebraduras, trincas, cortes e abrasões.

As operações mecanizadas, aplicadas durante e após a colheita, são potencialmente geradoras de danificações mecânicas às sementes. Assim, a debulha, o processamento, o armazenamento e a distribuição têm recebido recomendações voltadas à redução das injúrias (Pollock \& Roos, 1972: Popinigis, 1977; Carvalho \& Nakagawa, 1983). Segundo Finch et al. (1980), as 
sementes de milho devem ser colhidas "em espiga" com teor de água entre 20 e $25 \%$, secadas até 15 a $18 \%$ para, em seguida, ser realizada a debulha. Por outro lado, Gonçalves (1981) concluiu que os métodos de colheita com debulha associada não se mostraram inferiores aos com debulha isolada, concordando com Craig (1977) ao recomendar colheita e debulha conjuntas. Sato (1991) observou que as sementes, provenientes de colheita com debulha realizada mecanicamente no campo, apresentaram maior incidência de danos mecânicos; entretanto, quando a colheita em espigas foi conduzida sem seleção posterior, não foram observadas diferenças na germinação das sementes provenientes dos diferentes métodos de debulha.

Os efeitos das injúrias sobre as sementes podem ser classificados como imediatos, observáveis em seguida ao dano, ou latentes, verificáveis, normalmente, durante 0 armazenamento (Toledo \& Marcos Filho, 1977; Carvalho \& Nakagawa, 1983).

As danificações mecânicas, não suficientes para destruir as estruturas essenciais das sementes (danos não visíveis), proporcionam aumento no número de plântulas anormais, maior susceptibilidade à ação dos microrganismos, maior sensibilidade aos tratamentos químicos e diminuição do potencial de armazenamento, principalmente, em safras transcorridas sob condições ambientais desfavoráveis na maturação e na colheita (Bewley \& Black, 1985); além disso, os efeitos cumulativos das danificações mecânicas afetam negativamente a germinação, o vigor e o potencial de produtividade das sementes (Bunch, 1960; Copeland, 1972; Fagundes et al, 1972; Carvalho \& Nakagawa, 1988).

As injúrias surgidas no processo de produção de sementes, com extensão e direcionamento pouco controláveis, têm sido relatadas como prejudiciais ao desempenho (Delouche \& Andrews,1964; Popinigis, 1977; Marcos Filho, 1986). Contudo, o efeito gerado ganha importância em virtude da abertura de canais para a entrada de microrganismos patogênicos Soave \& Wetzel (1987) e é agravado, paralelamente, quando as injúrias se aproximam 
do embrião (Wortman \& Rinke, 1951 e Carvallho \& Nakagawa, 1983). Por outro lado, algumas pesquisas, que aplicaram danos controlados e dirigidos ao endosperma córneo das sementes de milho, não constataram prejuízos relacionados ao desempenho (Koehler, 1935; Wortman \& Rinke, 1951; Mckeen \& Macdonald, 1976; Silva et al. 1994).

Os fatores que controlam as injúrias, segundo Carvalho \& Nakagawa (1983), são a intensidade, o número e o local do impacto, o teor de água, o tamanho, a forma, a espessura do tegumento, o tipo de tecido de reserva e a posição do eixo embrionário das sementes.

Os tecidos injuriados são mais susceptiveis à invasão por fungos saprófitas ou parasitas, tanto no campo como durante o armazenamento (Neergaard, 1979). A localização da injúria deve ser considerada. Por exemplo, no trigo, injúrias no pericarpo, na região que cobre o endosperma, determinam $100 \%$ de infecção de Penicillium e Rhizopus; contudo, se a ruptura se der na região do embrião, a semente é pouco afetada por esses fungos; adicionalmente, sementes com pericarpo injuriado, aumentando as trocas de vapor de água com o meio ambiente, podem hidratar e tornarem-se mais vulneráveis aos fungos de armazenamento Soave \& Wetzel (1987).

A influência da danificação do pericarpo das sementes de milho na germinação, estudada por Meyers (1924), gerou redução de, aproximadamente, $30 \%$ no "stand" e menor vigor das plântulas em condições de campo desfavoráveis para a emergência. Entretanto, durante os dois anos de estudo, a redução da população não afetou a produção, com exceção do caso em que as sementes danificadas foram inoculadas artificialmente com Penicillium sp.

A influência, do dano na semente de milho na produção, foi estudada por Koehler (1935) que constatou perdas de 12 a $16 \%$, quando utilizou sementes com perfurações na "coroa" , e de 18 a $23 \%$ quando removeu o pericarpo de toda a "coroa". Concluiu que um corte no pericarpo da semente, na região do endosperma córneo no lado oposto ao do embrião, não causou prejuízo à população ou à produção. Em solo úmido, Aspergilus flavus e 
Aspergilus tamarii causaram prejuízos ao desempenho das sementes com pericarpo danificado na "coroa"; em solo seco, as sementes injuriadas na "coroa" sofreram ataque de Gibberella saubinetti. Contudo, Penicillium oxalicum foi ativo em sementes danificadas na "coroa" sob ambas as condições de umidade do solo.

As sementes com o tegumento, ou estrutura equivalente, intacto são mais resistentes ao ataque de fungos durante a germinação e durante o armazenamento. Hurd (1921) instalou sementes de trigo e cevada, com o pericarpo danificado, em papel mata borrão pulverizado com esporos de Penicillium sp. Quando o pericarpo apresentava-se partido na região sobre o endosperma, a infecção dos fungos reduziu a germinação e ocasionou a morte das plântulas. As sementes intactas, ou com o pericarpo danificado somente na região do embrião, germinaram normalmente nas mesmas condições.

Tatum \& Zuber (1943), trabalhando com sementes de milho, observaram relação estreita entre a injúria do pericarpo na região sobre o embrião e a população de plantas e produção no campo. Concluíram que a ação negativa do dano depende de sua severidade que, quando ampliada, facilita a colonização do fungo no embrião.

As sementes danificadas são mais sensiveis aos danos químicos durante o tratamento com defensivos e mais susceptiveis ao ataque de microrganismos de solo (Wortman \& Rinke, 1951; Craig, 1977 e Rocha et al, 1984). Segundo Nijenstein (1986), os fungos patogênicos de solo foram as mais importantes causas de mortalidade de sementes sob condições de estresse.

Hoppe (1948), estudando fungicidas mercuriais em milho, destinados à proteção das sementes danificadas, concluiu que as sementes injuriadas na coroa e na base não mostraram sinais de fitotoxicidade na germinação e na emergência; as sementes com injúrias, próximas ao embrião ou no embrião, apresentavam sintomas de fitotoxicidade aos fungicidas. Dale (1959) em experimento com milho que testava a proteção proporcionada por fungicidas às sementes sadias, sementes com pericarpo danificado na coroa e sementes 
injuriadas na região da radícula, verificou que, sob a ação dos fungicidas, a ação desfavorável das danificações foi anulada.

Dessa maneira, o conhecimento estabelecido sugere haver importância da interferência do dano mecânico no desempenho das sementes, particularmente em função de sua associação com o estabelecimento de microrganismos. Contudo, é escasso o número de pesquisas direcionadas ao entendimento dessas relações que, em sua essência, abrigam quantidade expressiva de variáveis. 


\section{MATERIAL E MÉTODOS}

O trabalho foi realizado nos Laboratórios de Análise de Sementes e de Patologia de Sementes da Escola Superior de Agricultura "Luiz de Queiroz"I USP.

\subsection{Sementes}

As sementes de milho hibrido (cultivar $A G$ 352) foram colhidas manualmente em espiga e secadas em equipamento estacionário. A debulha, limpeza e classificação foram realizadas em equipamentos de acionamento manual, objetivando dificultar a ocorrência de danos mecânicos. O lote experimental foi constituído pelas sementes puras que, retidas na peneira com crivos circulares de $22 / 64$ de polegada, representaram a maior fração da população classificada em peneiras dispostas em ordem decrescente, com crivos circulares de diâmetro variando em 1/64 de polegada, no intervalo de 25/64 a 18/64 de polegada.

\subsection{Obtenção dos tratamentos}

Após a caracterização qualitativa do lote original, as sementes foram danificadas, através do uso de bisturi equipado com limitador de ação, com cortes de $1 \mathrm{~mm}$ de comprimento e $2 \mathrm{~mm}$ de profundidade. Dessa maneira, sem que os eixos embrionários fossem atingidos, foram obtidas sementes intactas 
(Do) e danificadas nas regiōes da calota endospermática $\left(D_{1}\right)$, do ápice do escutelo $\left(D_{2}\right)$ e da camada negra $\left(D_{3}\right)$, conforme as indicações da Figura 1.

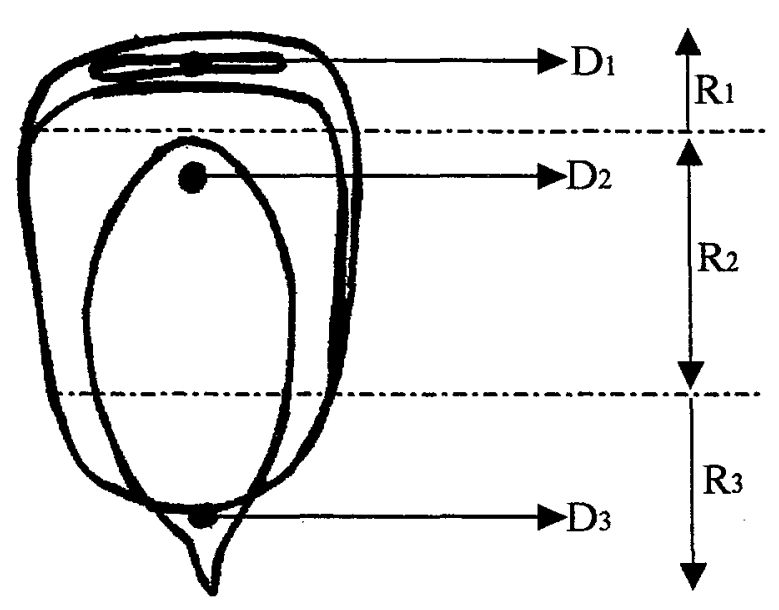

Figura 1. Localizações dos danos $D_{1}$ (calota endospermática), $D_{2}$ (ápice do escutelo) e D3 (camada negra), provocados nas sementes, e regiões ( $R_{1}, R_{2}$ e $R_{3}$ ) consideradas na determinação da densidade ponderada de infecção.

Posteriormente, as sementes foram submetidas aos seguintes procedimentos denominados etapas de inoculação:

- Assepsia: as sementes foram desinfetadas superficialmente com hipoclorito de sódio (1\%) por 3 minutos e lavadas com água destilada; após, foram colocadas para secar à sombra por um período de 24 horas.

- Assepsia + BDA: após a desinfecção superficial, as sementes foram colocadas em placas de Petri contendo meio de cultura BDA (200 g de batata, $15 \mathrm{~g}$ de ágar, $20 \mathrm{~g}$ de dextrose e $1000 \mathrm{ml}$ de água destilada) onde permaneceram por 48 horas em câmara de incubação sob $20 \pm 2^{\circ} \mathrm{C}$ e luz alternada (12 horas de luz branca fluorescente/ 12 horas de escuro); em seguida, foram colocadas para secar à sombra durante 24 horas. 
- Assepsia + BDA + Fungo: primeiramente, foi obtida a cultura pura de cada fungo, em tubos de ensaio, com posterior desenvolvimento em placas de Petri contendo meio de cultura BDA. Quando os fungos se desenvolveram, na superfície do meio de cultura BDA, foi feita repicagem para as placas onde se deram, individualizadamente para cada microrganismo, as inoculações artificiais, pelo método de contato, através da agitação das sementes desinfectadas superficialmente com as fontes de inóculo (Aspergillus sp., Penicillium sp. e Fusarium moniliforme); posteriormente, foi realizada secagem à sombra durante 24 horas.

Assim, cada uma das fontes de inóculo constituiu um experimento isolado que abrigou os tratamentos representados pelos danos mecânicos ( $D_{0}$, $D_{1}, D_{2}$ e $D_{3}$ ) e pelas etapas de inoculação (Assepsia, Assepsia + BDA e Assepsia + BDA + fungo).

\subsection{Determinações}

\subsubsection{Caracterização do lote original}

a) Teste de germinação: foi realizado em 100 sementes por repetição, instaladas em rolo de papel toalha sob $25^{\circ} \mathrm{C}$. O peso de água utilizado para embebição foi o equivalente a 2,5 vezes o do substrato seco. As contagens foram realizadas aos 4 e 7 dias após a semeadura e, a avaliação, efetuada segundo os critérios estabelecidos pelas Regras de Análise de Sementes (Brasil, 1992), computou a freqüência de plântulas normais.

b) Teste de tetrazólio: realizado com 50 sementes por repetição. As sementes foram pré-condicionadas em papel toalha umedecido e colocadas em germinador $\left(30^{\circ} \mathrm{C}\right)$ por 18 horas. Decorrido este período, as sementes foram imersas em solução $0,075 \%$ de sal de tetrazólio (cloreto 2, 3, 5-trifeniltetrazólio) e mantidas, durante 3 horas, a $30^{\circ} \mathrm{C}$ em estufa para acelerar a reação. Após 
este periodo, as sementes foram lavadas em água corrente e conservadas imersas em água até a avaliação conduzida segundo os critérios descritos pelas Regras de Análise de Sementes (Brasil, 1992).

c) Teste de dano mecânico: foi empregado o teste da tintura de iôdo. Duas amostras de 100 sementes por repetição foram colocadas em copos plásticos, adicionando-se tintura de iôdo (solução a $4 \%$ ) em quantidade suficiente para cobrir as sementes que, após cinco minutos de imersão, foram lavadas. Considerou-se como danificadas as sementes que apresentaram sinais de cor roxa provenientes da reação entre o iôdo e o amido. Os resultados foram expressos em porcentagem, segundo as recomendações de Marcos Filho et al. (1987).

d) Teste de sementes infestadas: foram empregadas 2 amostras de 100 sementes por repetição. Os resultados, expressos em porcentagem, consideraram as sementes atacadas por pragas de armazenamento, segundo os critérios descritos pelas Regras para Análise de Sementes (Brasil, 1992).

e) Teste de sanidade: foram utilizadas 50 sementes por repetição. Nas câmaras úmidas, constituídas por placas de Petri, foram colocadas três folhas de papel de filtro previamente embebidas em água destilada sendo, posteriormente, as sementes distribuídas com o auxílio de pinça flambada. As câmaras úmidas foram postas para incubação, no interior de estufa mantida a $20 \pm 2^{\circ} \mathrm{C}$, por um dia, com alternância de luz e escuro de 12 horas. A seguir, foram retiradas e colocadas em congelador por 24 horas, sendo depois retornadas à incubação no interior da estufa durante 7 dias. Após este período, foram avaliadas as incidências de fungos dos gêneros Aspergillus, Penicillium e Fusarium nas sementes, com os auxílios de microscópios estereoscópico e composto. 


\subsubsection{Avaliações dos tratamentos}

Foram aplicados, seguindo os critérios descritos em 3.3.1., os testes de germinação, de dano mecânico e de sanidade. Além destes, foram conduzidas as seguintes determinações:

a) Grau de umidade: foi utilizado o método de estufa, a $105 \pm 3^{\circ} \mathrm{C}$ durante 24 horas, empregando 2 amostras por repetição, conforme as indicações das Regras para Análise de Sementes (Brasil, 1992). Os resultados foram expressos em porcentagem na base úmida.

b) Teste de envelhecimento artificial: 50 sementes por repetição, dispostas em mini-câmaras (gerbox adaptado) com $40 \mathrm{ml}$ de água destilada no seu interior, foram mantidas em câmara sob $42^{\circ} \mathrm{C}$ e $100 \%$ U. R., durante 72 horas, de acordo com as recomendações de Marcos Filho et al. (1987). A seguir, foram submetidas ao teste de germinação para obtenção da porcentagem de plântulas normais presentes no quarto dia após a semeadura.

c) Teste de frio: foi conduzido utilizando-se substrato resultante da mistura de $1 / 3$ de terra (proveniente de área cultivada com milho) e 2/3 de areia colocada em caixa plástica. Após a semeadura de 50 sementes por repetição, procedeu-se à irrigação até que fosse atingida $60 \%$ da capacidade de retenção de água na mistura. Os recipientes foram mantidos tampados e colocados em câmara $\left(10^{\circ} \mathrm{C}\right)$ durante 7 dias, conforme o recomendado por Marcos Filho et al. (1985); após este período, foram retirados e colocados em ambiente não controlado, onde permaneceram por 7 dias para a contagem e cálculo percentual das plântulas emersas.

d) Teste de comprimento da plântula: foi realizado, em rolo de papel umedecido como $\circ$ descrito para $\circ$ teste de germinação, empregando 3 
amostras de 10 sementes por repetição. A semeadura foi efetuada sobre uma linha traçada no terço superior do papel em sentido longitudinal. Os rolos, embalados em sacos plásticos, foram dispostos verticalmente no germinador (Krzyzanowski et al., 1991) e mantidos por 4 dias sob temperatura de $25^{\circ} \mathrm{C}$. Decorrido este período, todos os indivíduos foram medidos em $\mathrm{mm}$. O comprimento médio da plântula foi obtido pelo quociente entre a soma das medidas tomadas e o número total de indivíduos instalados em cada amostra.

e) Teste de emergência das plântulas: foram instaladas 50 sementes por repetição, em campo mantido sob irrigação, em linhas de $2,0 \mathrm{~m}$ espaçadas de $0,3 \mathrm{~m}$ entre si. A avaliação foi realizada aos 21 dias após a semeadura, computando-se a porcentagem de plântulas emersas em método semelhante ao descrito por Nakagawa (1994).

f) Estimativa da densidade ponderada de infecção (DPI): realizada durante a interpretação do teste de sanidade, considerou, exclusivamente, as etapas de inoculação que receberam os fungos (Assepsia + BDA + Fungo) e as regiōes $R_{1}, R_{2}$ e $R_{3}$ (Figura 1) da superfície das sementes que abrigavam, respectivamente, os locais de aplicação dos danos $D_{1}, D_{2}$ e $D_{3}$. $O$ ataque de patógenos, estimado através de notas $(0,1$ e 2$)$ segundo a área ocupada, foi representado, por região, pela média das notas atribuídas aos indivíduos. Foi aplicada a equação desenvolvida por MacKinney, para o cálculo do índice de doenças em plantas, adaptada por Machado \& Martins (1999) para a estimativa da densidade ponderada de infecção em sementes:

$D P I=\frac{\left(f_{0} \times n_{0}\right)+\left(f_{1} \times n_{1}\right)+\left(f_{2} \times n_{2}\right)}{F \times N} \times 100$, onde:

$f_{0}, f_{1}$ e $f_{2}=$ número respectivo de indivíduos em cada uma das notas

$\mathrm{n}_{0}=0$ (nota para ausência de fungos na região)

$n_{1}=1$ (nota para 1 a $40 \%$ da região ocupada por fungos) 
$\mathrm{n}_{2}=2$ (nota para 41 a $100 \%$ da região ocupada por fungos)

$\mathrm{F}=\mathbf{2 0 0}$ (número total de indivíduos)

$\mathrm{N}=2$ (nota máxima atribuível)

\subsection{Delineamento experimental e análise estatística}

Foi empregado o delineamento inteiramente casualizado em esquema fatorial com quatro repetições.Os dados obtidos na avaliação dos tratamentos, pelos testes fisiológicos (germinação, tetrazólio, envelhecimento artificial, frio, comprimento de plântula e emergência das plântulas) e pelo teste de densidade ponderada de infecção, foram submetidos à análise estatística (Tabelas 1a e 1b), por experimento, e tiveram as médias comparadas pelo teste de Tukey (5\%). Foi utilizado o Sistema de Análise Estatística - SANEST (Zonta \& Machado, 1984).

Tabela 1a. Esquema da análise estatística aplicado, por experimento, nos dados dos testes fisiológicos realizados na avaliação dos tratamentos.

\begin{tabular}{lc}
\hline Causas de Variação & Graus de Liberdade \\
\hline Danos $(D)$ & 3 \\
Etapas de inoculação $\left(E_{i}\right)$ & 2 \\
$D \times E_{i}$ & 6 \\
Resíduo & 36 \\
\hline TOTAL & 47 \\
\hline
\end{tabular}


Tabela 1b. Esquema da análise estatística aplicado, por experimento, nos dados do teste da densidade ponderada de infecção realizado na avaliação dos tratamentos.

\begin{tabular}{lc}
\hline Causas de Variação & Graus de Liberdade \\
\hline Danos (D) & 3 \\
Regiões (R) & 2 \\
DxR & 6 \\
Resíduo & 36 \\
\hline TOTAL & 47 \\
\hline
\end{tabular}




\section{RESULTADOS E DISCUSSÃO}

\subsection{Caracterização do lote original}

Os dados (Tabela 2), relativos ao lote utilizado, mostraram a existência de qualidade fisiológica próxima da máxima, segundo as indicações fornecidas pelos testes de germinação e de tetrazólio; além disso, detectaram ausências de dano mecânico e de infestação de insetos nas sementes. Estas características, considerando os objetivos da pesquisa, eram buscadas para permitir a devida medição dos efeitos dos tratamentos adotados, especialmente os relacionados à aplicação das injúrias mecânicas.

Por outro lado, a desejada ausência de fungos, demandada pelas avaliações relacionadas à inoculação, não foi conseguida (Tabela 2) no lote empregado e, dessa forma, tornou-se necessária a inclusão da assepsia nos procedimentos para inoculação dos patógenos.

Tabela 2. Dados de qualidade das sementes (lote original) obtidos anteriormente à aplicação dos tratamentos.

\begin{tabular}{lc}
\hline Determinações & Dados médios(\%) \\
\hline 1. Germinação & 99 \\
2. Tetrazólio & 100 \\
3. Dano mecânico & 0 \\
4. Sementes infestadas & 0 \\
5. Sanidade: & \\
Aspergillus spp. & 7,6 \\
Penicillium spp. & 15,5 \\
Fusarium moniliforme & 14,5 \\
\hline
\end{tabular}




\subsection{Avaliações dos tratamentos}

Os graus de umidade (Tabela 3) apresentaram uniformidade suficiente para sugerir ausência de efeitos dos tratamentos $e$, portanto, reduzida interferência nas demais determinações realizadas, particularmente as destinadas à avaliação do desempenho fisiológico das sementes. Os danos mecânicos (Tabela 4), ausentes em $D_{0}$, foram invariavelmente verificados em todas as sementes pertencentes aos tratamentos $D_{1}, D_{2}$ e $D_{3} \mathrm{e}$, dessa forma, ficou atestada a existência das injúrias-objeto do estudo.

O teste de sanidade (Tabela 5) detectou incidências de 100\% para todos os fungos inoculados nos respectivos experimentos; contudo, contrariamente ao esperado, indicou que a assepsia realizada não erradicou o Fusarium moniliforme que, apesar de não apresentar incidências superiores a 11,5\% em Assepsia e Assepsia + BDA, se manteve invariavelmente presente em todos os experimentos. A densidade ponderada de infecção (Tabela 6), estimando a ocupação de microrganismos nas sementes, mostrou, na ausência de dano $\left(D_{0}\right)$ em todos os experimentos, a ampliação de valores no sentido da região da calota endospermática $\left(R_{1}\right)$ para a da camada negra $\left(R_{3}\right)$. Consideradas isoladamente as danificações $D_{1}, D_{2}$ e $D_{3}$ no experimento 3 (Fusarium moniliforme), as maiores áreas colonizadas ocorreram nas regiões $R_{1}, R_{2}$ e $R_{3}$ que correspondiam, respectivamente, às de realização dos danos; no experimento 1 (Aspergillus sp.), esta ocorrência esteve presente em $D_{2} \in D_{3}$ e ausente em $D_{1}$. No experimento 2 (Penicillium sp.), os dados não evidenciaram relações diretas entre o local de realização do dano e a superfície colonizada pelos patógenos $e$, da mesma forma que o verificado em $D_{0}$ em todos os experimentos, destacaram a ocorrência de maiores áreas ocupadas nas regiões próximas ao embrião $\left(R_{2}\right.$ e $\left.R_{3}\right)$ do que na da calota endospermática $\left(R_{1}\right)$. Assim, os dados relativos à Tabela 6 , particularmente para Aspergillus $\mathrm{sp}$. e para Fusarium moniliforme, indicaram que o local da danificação favorece o 
estabelecimento dos microrganismos que, nas sementes intactas, concentra-se na região da ligação das sementes com o sabugo (camada negra).

$\mathrm{Na}$ observação dos dados de germinação (Tabela 7), dentro das etapas de inoculação, verifica-se predominância da inferioridade de $D_{2}$ e $D_{3}$, em relação a $D_{0}$ e $D_{1}$, particularmente nos procedimentos que incluíram os fungos; excetuando-se a superioridade de $D_{0}$ em relação a $D_{1}$, observada na presença de Fusarium moniliforme, as duas danificações apresentaram comportamento semelhante entre si nos demais casos. Fixadas as danificações, houve indicação de tendência de redução nos valores de Assepsia + BDA + fungos em relação à Assepsia. Este efeito, em comparações dentro das danificações $D_{1}, D_{2}$ e $D_{3}$, deixou de ocorrer, exclusivamente, com Penicillium $s p$ em $D_{1}$; nas sementes não danificadas $\left(D_{0}\right)$, contudo, foi observado unicamente no experimento inoculado com Fusarium moniliforme. Assim, levando em conta as informações existentes na Tabela 7 , a germinação foi negativamente influenciada, especialmente, quando os danos $D_{2}$ e $D_{3}$ estiveram associados às inoculações com os fungos.

A viabilidade, estimada pelo teste de tetrazólio (Tabela 8), foi quantitativamente menos afetada pelos tratamentos do que a germinação (Tabela 7); contudo, as tendências observadas foram semelhantes nos dois testes. Especificamente em relação aos fungos, o teste de tetrazólio tem , reconhecidamente, baixa eficiência na detecção de efeitos uma vez que os fungos, na maioria dos casos, agravam a sua ação patogênica durante o desenvolvimento da plântula, não analisado pelo teste.

O teste de envelhecimento artificial (Tabela 9), mais definidamente na presença dos fungos, destacou prejuízos qualitativos invariáveis das danificações $D_{1}, D_{2}$ e $D_{3}$ em relação às sementes intactas $\left(D_{0}\right)$; com os fungos não inoculados (Assepsia e Assepsia + BDA), esses prejuízos tornaram-se menos evidentes em $D_{1}$. $A$ inoculação dos fungos, quando confrontada com a Assepsia dentro das danificações, provocou prejuizos generalizados em $D_{0}$ e $D_{1}$; nos demais casos $\left(D_{2}\right.$ e $\left.D_{3}\right)$, o fato se repetiu exclusivamente no 
experimento com Fusarium moniliforme em $D_{2}$. Fazendo referência à Assepsia + $B D A$, foram observadas, em todos os experimentos, várias inferioridades nas comparações com Assepsia + BDA + fungos, inclusive em $D_{0}$ : este fato não apresentou indicações que proporcionassem a elaboração de alguma hipótese capaz de elucidá-lo. Assim, a análise dos dados obtidos indicou que, nas sementes afetadas negativamente pelas danificações $\left(D_{2}\right.$ e $\left.D_{3}\right)$, os prejuízos fisiológicos não foram agravados com as presenças de Aspergillus sp. e de Penicillium sp.; considerado o Fusarium moniliforme, este comportamento ficou restrito a $D_{3}$. Por outro lado, nas sementes intactas $\left(D_{0}\right)$ ou danificadas sem a promoção de efeitos fisiológicos $\left(D_{1}\right)$, a ação negativa dos fungos foi constatada em todos os casos estudados.

Os dados do teste de frio (Tabela 10), excetuando-se os da danificação $\mathrm{D}_{1}$ em Assepsia + BDA + Penicillium sp., detectaram efeitos fisiológicos negativos das danificações $D_{1}, D_{2}$ e $D_{3}$ nas comparações com $D_{0}$, independentemente da etapa de inoculação considerada. Entre as etapas de inoculação, as de Assepsia + BDA + fungos, excetuando-se a de Penicillium sp. em $D_{1}$ e $D_{3}$ e as demais em $D_{1}$, geraram prejuízos quando comparadas com a Assepsia. Dessa forma, o teste de frio detectou, de modo mais significativo do que o observado no teste de envelhecimento artificial (Tabela 9), evidências da soma de prejuizos qualitativos das danificações $D_{2}$ e $D_{3}$ com as etapas de inoculação que continham os fungos.

O teste de comprimento da plântula (Tabela 11), dentro de todas as etapas de inoculação, indicou inferioridades de $D_{2}$ e de $D_{3}$ nas comparações com $D_{0}$ e com $D_{1}$. Adicionalmente, as etapas de Assepsia + BDA + fungos geraram decréscimos qualitativos, em relação à Assepsia, dentro de todas as danificações. Dessa maneira, os dados obtidos sugeriram que a redução qualitativa provocada pelas inoculações dos fungos, apesar de ocorrer nas sementes intactas $\left(D_{0}\right)$, foi ampliada na presença das injúrias $\left(D_{2}\right.$ e $\left.D_{3}\right)$ que, independentemente das etapas de inoculação, mostraram-se capazes de gerar prejuízos fisiológicos. 
No teste de emergência das plântulas (Tabela 12), os danos $D_{2}$ e $D_{3}$, em todas as etapas de inoculação, reduziram a qualidade fisiológica nas comparações com $D_{0}$, em tendência similar às verificadas nos testes de germinação (Tabela 7), de envelhecimento artificial (Tabela 9), de frio (Tabela 10) e de comprimento da plântula (Tabela 11). Dentro das danificações, com exceção feita à Assepsia + BDA + Aspergillus sp. em $\mathrm{D}_{0}$, as etapas de Assepsia + BDA + fungos trouxeram prejuízos nos confrontos com Assepsia, em $D_{0}, D_{1}$ e $D_{2}$, e não mostraram os efeitos negativos verificados nos demais testes fisiológicos em $D_{3}$.

Assim, levando em conta o conjunto dos dados provenientes dos testes realizados, foram possíveis as seguintes observações:

- Os danos mecânicos, isoladamente, reduziram a qualidade fisiológica das sementes em intensidade variável e dependente das suas localizações. Sob este aspecto, os aplicados no ápice do escutelo $\left(D_{2}\right)$ e na região da camada negra $\left(D_{3}\right)$ foram mais prejudiciais do que o realizado na calota endospermática $\left(D_{1}\right)$, com localização mais distante do embrião. Esta constatação, relacionando a gravidade do dano com a proximidade ao embrião, foi similarmente referida por Wortman \& Rinke (1951) e Carvalho \& Nakagawa (1983). Por outro lado, pesquisas realizadas por Koelher (1935), Mackeen \& Macdonald (1976) e Silva et al. (1994), que aplicaram danos controlados e dirigidos ao endosperma córneo das sementes de milho, não constataram prejuízos relacionados ao desempenho.

- As etapas de inoculação que incluíram os fungos, independentemente da presença de danos mecânicos, tenderam a afetar negativamente a qualidade das sementes. Quando comparados entre si, Aspergillus sp. e Fusarium moniliforme geraram maiores prejuizos do que Penicillium sp. Resultados similares, associando a presença de fungos com a depressão da qualidade fisiológica das sementes, foram relatados por Dhingra et al. (1980), Filgueiras (1981) e Lucca Filho (1985). Wu \& Cheng (1990), trabalhando com fungos associados às sementes de sorgo, entre os quais Fusarium moniliforme, 
verificaram a existência de relações entre os patógenos e os prejuízos no desempenho das sementes. Da mesma forma, Tanaka \& Correa (1981), em sementes de feijão inoculadas com Aspergillus spp. e Penicillium spp. previamente ao armazenamento, observaram influências da ação dos fungos na germinação e na emergência das plântulas. Em milho, Lópes \& Christensen (1967) evidenciaram redução na germinação decorrente da incidência de Aspergillus flavus inoculado nas sementes.

- Os prejuizos, advindos das associações entre as danificações e os fungos inoculados, foram mais freqüentes quando reunidos os danos próximos ao embrião $\left(D_{2} \in D_{3}\right)$ com os fungos Aspergillus sp. e Fusarium moniliforme. Nestes casos, a região danificada tendeu a se constituir em local facilitador para a colonização dos fungos. Similarmente, Delouche \& Andrews (1964), Popinigis (1977) e Marcos Filho (1986) relataram que as injúrias são prejudiciais ao desempenho e, neste sentido, Soave \& Wetzel (1987) observaram que o efeito gerado ganha importância em virtude de propiciar abertura de canais para a entrada de microrganismos. Em sementes de milho, Tatum \& Zuber (1943) observaram que a ação negativa do dano depende de sua severidade que, quando ampliada, facilita a colonização do fungo; da mesma forma, Meyers (1924) utilizando sementes de milho danificadas e portadoras de Penicillium sp, verificou reduções nas populações de plantas afetando a produção durante dois anos de estudo. Paralelamente, Moore (1974) relatou que, em comparação com a injúria do tipo "quebramento", o "amassamento" eleva os efeitos latentes em virtude de, aumentando o contato de tecidos lesionados com os intactos, estimular a formação de um centro de infecção utilizado por fungos de armazenamento como local de estabelecimento na semente. 
Tabela 3. Determinação do grau de umidade: dados (\%) obtidos após a aplicação dos tratamentos.

\begin{tabular}{|c|c|c|c|c|c|}
\hline \multirow[b]{2}{*}{ Experimentos } & \multirow[b]{2}{*}{ Etapas de inoculação } & \multicolumn{4}{|c|}{ Danificações } \\
\hline & & Do & $\mathrm{D}_{1}$ & $\bar{D} 2$ & D3 \\
\hline \multirow{3}{*}{1} & Assepsia & 12,4 & 12,6 & 12,2 & 12,4 \\
\hline & Assepsia + BDA & 12,0 & 12,5 & 12,3 & 12,2 \\
\hline & Assepsia + BDA + Aspergillus sp. & 12,3 & 12.3 & 12.2 & 12,2 \\
\hline \multirow{3}{*}{2} & Assepsia & 12,5 & 12,4 & 12,4 & 12,3 \\
\hline & Assepsia + BDA & 11,9 & 12,4 & 12,5 & 12,2 \\
\hline & Assepsia + BDA + Penicillium sp. & 12,2 & 12.2 & 12,4 & 12,1 \\
\hline \multirow{3}{*}{3} & Assepsia & 12,4 & 12,4 & 12,4 & 12,2 \\
\hline & Assepsia + BDA & 12,4 & 12,6 & 12,4 & 12,2 \\
\hline & Assepsia + BDA + Fusarium moniliforme. & 12,6 & 12,5 & 12,2 & 12,2 \\
\hline
\end{tabular}


Tabela 4. Teste de dano mecânico: dados (\%) obtidos após a aplicação dos tratamentos.

\begin{tabular}{|c|c|c|c|c|c|}
\hline \multirow[b]{2}{*}{ Experimentos } & \multirow[b]{2}{*}{ Etapas de inoculacão } & \multicolumn{4}{|c|}{ Danificações } \\
\hline & & Do & $\mathrm{D}_{1}$ & $\mathrm{D} 2$ & D3 \\
\hline \multirow[t]{3}{*}{ 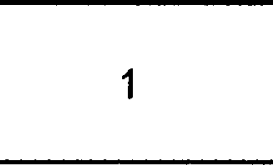 } & Assepsia & zero & 100 & 100 & 100 \\
\hline & Assepsia + BDA & zero & 100 & 100 & 100 \\
\hline & Assepsia + BDA + Aspergillus sp. & zero & 100 & 100 & 100 \\
\hline \multirow{3}{*}{2} & Assepsia & zero & 100 & 100 & 100 \\
\hline & Assepsia + BDA & zero & 100 & 100 & 100 \\
\hline & Assepsia + BDA + Penicillium sp. & zero & 100 & 100 & 100 \\
\hline \multirow{3}{*}{3} & Assepsia & zero & 100 & 100 & 100 \\
\hline & Assepsia + BDA & zero & 100 & 100 & 100 \\
\hline & Assepsia + BDA + Fusarium moniliforme & zero & 100 & 100 & 100 \\
\hline
\end{tabular}


Tabela 5. Teste de sanidade: dados (\%) da incidência de fungos obtidos após a aplicação dos tratamentos.

\begin{tabular}{|c|c|c|c|c|c|c|}
\hline \multirow[b]{2}{*}{ Experimentos } & \multirow[b]{2}{*}{ Etapas de inoculação } & \multirow[b]{2}{*}{ Fungos } & \multicolumn{3}{|c|}{ Danificações } & \multirow[b]{2}{*}{ D3 } \\
\hline & & & Do & $D_{1}$ & D2 & \\
\hline \multirow{9}{*}{1} & Assepsia & Aspergillus spp. & 0,0 & 0,0 & 0,0 & 0,0 \\
\hline & & Penicillium spp. & 0,0 & 0,0 & 0,0 & 0,0 \\
\hline & & Fusarium moniliforme & 10,0 & 7,0 & 6,0 & 7,0 \\
\hline & Assepsia + BDA & Aspergillus spp. & 0,0 & 0,0 & 0,0 & 0,0 \\
\hline & & Penicillium spp. & 0,0 & 0,0 & 0,0 & 0,0 \\
\hline & & Fusarium moniliforme & 2,5 & 6,0 & 11,0 & 15,5 \\
\hline & Assepsia + BDA + Aspergillus sp. & Aspergillus spp. & 100,0 & 100,0 & 100,0 & 100,0 \\
\hline & & Penicillium spp. & 0,0 & 0,0 & 0,0 & 0,0 \\
\hline & & Fusanium moniliforme & 1,5 & 1,5 & 1,5 & 2,5 \\
\hline \multirow{9}{*}{2} & Assepsia & Aspergillus spp. & 0,0 & 0,0 & 0,0 & 0,0 \\
\hline & & Penicillium spp. & 0,0 & 0,0 & 0,0 & 0,0 \\
\hline & & Fusarium moniliforme & 2,5 & 6,0 & 11,0 & 15,5 \\
\hline & Assepsia + BDA & Aspergillus spp. & 0,0 & 0,0 & 0,0 & 0,0 \\
\hline & & Penicillium spp. & 0,0 & 0,0 & 0,0 & 0,0 \\
\hline & & Fusanium moniliforme & 2,0 & 4,0 & 9,0 & 13,5 \\
\hline & Assepsia + BDA + Penicillium sp. & Aspergillus spp. & 0,0 & 0,0 & 0,0 & 0,0 \\
\hline & & Penicillium spp. & 100,0 & 100,0 & 100,0 & 100,0 \\
\hline & & Fusanium moniliforme & 2,5 & 2,0 & 1,5 & 5,5 \\
\hline \multirow{8}{*}{3} & Assepsia & Aspergillus spp. & 0,0 & 0,0 & 0,0 & 0,0 \\
\hline & & Penicillium spp. & 0,0 & 0,0 & 0,0 & 0,0 \\
\hline & & Fusarium moniliforme & 2,0 & 5,5 & 9,0 & 12,0 \\
\hline & Assepsia + BDA & Aspergillus spp. & 0,0 & 0,0 & 0,0 & 0,0 \\
\hline & & Penicillium spp. & 0,0 & 0,0 & 0,0 & 0,0 \\
\hline & & Fusarium moniliforme & 3,0 & 5,0 & 10,0 & 12,0 \\
\hline & Assepsia + BDA + F. moniliforme & Aspergillus spp. & 0,0 & 0,0 & 0,0 & 0,0 \\
\hline & & $\begin{array}{l}\text { Penicillium spp. } \\
\text { Fusarium moniliforme }\end{array}$ & $\begin{array}{c}0,0 \\
100,0\end{array}$ & $\begin{array}{c}0,0 \\
100,0\end{array}$ & $\begin{array}{c}0,0 \\
100,0\end{array}$ & $\begin{array}{c}0,0 \\
100,0\end{array}$ \\
\hline
\end{tabular}


Tabela 6. Densidade ponderada de infecção: dados (\%) obtidos após a aplicação dos tratamentos.

\begin{tabular}{|c|c|c|c|c|c|c|}
\hline \multirow[b]{2}{*}{ Experimentos } & \multirow[b]{2}{*}{ Etapas de inoculação } & \multirow[b]{2}{*}{ Regiōes } & \multicolumn{3}{|c|}{ Danificações } & \multirow[b]{2}{*}{$\bar{D} 3$} \\
\hline & & & Do & D1 & $\mathrm{D}_{2}$ & \\
\hline \multirow[t]{3}{*}{ 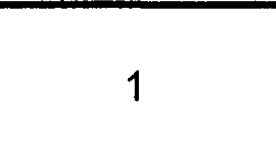 } & \multirow{3}{*}{ Assepsia + BDA + Aspergillus sp. } & R1 & $56 \mathrm{Cc}$ & $64 A b$ & $63 \mathrm{BC}$ & $53 \mathrm{Dc}$ \\
\hline & & R2 & $60 \mathrm{Cb}$ & 51Dc & $88 \mathrm{Aa}$ & $62 \mathrm{Bb}$ \\
\hline & & R3 & $76 \mathrm{Ba}$ & $65 \mathrm{Da}$ & $69 \mathrm{Cb}$ & $83 \mathrm{Aa}$ \\
\hline \multirow{3}{*}{2} & \multirow{3}{*}{ Assepsia + BDA + Penicillium sp. } & $\mathrm{R}_{1}$ & 53Dc & $66 \mathrm{BC}$ & $67 A b$ & $61 \mathrm{Cc}$ \\
\hline & & $\mathrm{R} 2$ & $56 \mathrm{Cb}$ & $81 \mathrm{Ba}$ & $81 \mathrm{Ba}$ & $88 \mathrm{Aa}$ \\
\hline & & $\mathrm{R}_{3}$ & $86 \mathrm{Aa}$ & $71 \mathrm{Cb}$ & $81 \mathrm{Ba}$ & $81 \mathrm{Bb}$ \\
\hline \multirow{3}{*}{3} & \multirow{3}{*}{ Assepsia + BDA + F. moniliforme } & $\mathrm{R}_{1}$ & $51 \mathrm{Bc}$ & $76 \mathrm{Aa}$ & $22 \mathrm{Cc}$ & 17Dc \\
\hline & & $\mathrm{R}_{2}$ & $53 \mathrm{Bb}$ & 20Dc & 63Aa & $38 \mathrm{Cb}$ \\
\hline & & R3 & $65 \mathrm{Aa}$ & $25 \mathrm{Db}$ & $48 \mathrm{Cb}$ & $58 \mathrm{Ba}$ \\
\hline
\end{tabular}

Para cada experimento, médias seguidas por mesma letra maíuscula na linha e por mesma letra minúscula na coluna não diferem estatisticamente, entre si, pelo teste Tukey $(P>0,05)$. 
Tabela 7. Teste de germinação: dados (\%) obtidos após a aplicação dos tratamentos.

\begin{tabular}{|c|c|c|c|c|c|}
\hline \multirow[b]{2}{*}{ Experimentos } & \multirow[b]{2}{*}{ Etapas de inoculação } & \multicolumn{4}{|c|}{ Danificações } \\
\hline & & Do & $D_{1}$ & $\mathrm{D}_{2}$ & D3 \\
\hline \multirow{3}{*}{1} & Assepsia & 98ABab & $99 \mathrm{Aa}$ & $96 \mathrm{Ba}$ & $90 \mathrm{Ca}$ \\
\hline & Assepsia + BDA & $99 \mathrm{Aa}$ & $99 \mathrm{Aa}$ & $79 \mathrm{Cb}$ & $86 \mathrm{Ba}$ \\
\hline & Assepsia + BDA + Aspergillus sp. & $97 \mathrm{Ab}$ & $96 \mathrm{Ab}$ & $65 \mathrm{Bc}$ & $46 \mathrm{Cb}$ \\
\hline \multirow{3}{*}{2} & Assepsia & $98 \mathrm{Aa}$ & $99 \mathrm{Aa}$ & $95 \mathrm{Ba}$ & $91 \mathrm{Ca}$ \\
\hline & Assepsia + BDA & $98 \mathrm{Aa}$ & $96 \mathrm{Ab}$ & $83 \mathrm{Bb}$ & $76 \mathrm{Cb}$ \\
\hline & Assepsia + BDA + Penicillium sp. & 98Aa & $98 \mathrm{Aa}$ & $86 \mathrm{Bb}$ & $72 \mathrm{Cb}$ \\
\hline \multirow{3}{*}{3} & Assepsia & $99 \mathrm{Aa}$ & $98 \mathrm{ABa}$ & $97 \mathrm{Ba}$ & $88 \mathrm{Ca}$ \\
\hline & Assepsia + BDA & $97 \mathrm{Ab}$ & $98 \mathrm{Aa}$ & $76 \mathrm{Cb}$ & $85 \mathrm{Bb}$ \\
\hline & Assepsia + BDA + Fusarium moniliforme & $98 \mathrm{Ab}$ & $86 \mathrm{Bb}$ & 35Dc & $68 \mathrm{Cc}$ \\
\hline
\end{tabular}

Para cada experimento, médias seguidas por mesma letra maíuscula na linha e por mesma letra minúscula na coluna não diferem estatisticamente, entre si, pelo teste Tukey $(P>0,05)$. 
Tabela 8. Teste de tetrazólio: dados (\%) de viabilidade obtidos após a aplicação dos tratamentos.

\begin{tabular}{clllll}
\hline & & \multicolumn{3}{c}{ Danificações } \\
\cline { 3 - 6 } Experimentos & & Etapas de inoculação & D1 & D2 & D3 \\
\hline \multirow{2}{*}{1} & Assepsia & $99 \mathrm{Aa}$ & $98 \mathrm{ABa}$ & $97 \mathrm{Ba}$ & $97 \mathrm{Ba}$ \\
& Assepsia + BDA & $97 \mathrm{Ab}$ & $98 \mathrm{Aa}$ & $96 \mathrm{Aa}$ & $96 \mathrm{Aa}$ \\
& Assepsia + BDA + Aspergillus sp. & $98 \mathrm{Ab}$ & $96 \mathrm{Bb}$ & $92 \mathrm{Bc}$ & $90 \mathrm{Ca}$ \\
\hline \multirow{2}{*}{2} & Assepsia & $96 \mathrm{Ba}$ & $98 \mathrm{Aa}$ & $96 \mathrm{Ba}$ & $90 \mathrm{Ca}$ \\
& Assepsia + BDA & $97 \mathrm{Aa}$ & $98 \mathrm{Aa}$ & $96 \mathrm{Aa}$ & $84 \mathrm{Bb}$ \\
& Assepsia + BDA + Penicillium sp. & $92 \mathrm{Bb}$ & $96 \mathrm{Ab}$ & $92 \mathrm{Bb}$ & $90 \mathrm{Ba}$ \\
\hline \multirow{2}{*}{3} & Assepsia & $97 \mathrm{ABa}$ & $99 \mathrm{Aa}$ & $95 \mathrm{BCa}$ & $94 \mathrm{Ca}$ \\
& Assepsia + BDA & $97 \mathrm{Aa}$ & $96 \mathrm{Ab}$ & $93 \mathrm{Bab}$ & $84 \mathrm{Cb}$ \\
& Assepsia + BDA + Fusarium moniliforme & $92 \mathrm{Ab}$ & $90 \mathrm{Ac}$ & $90 \mathrm{Ab}$ & $92 \mathrm{Aa}$ \\
\hline
\end{tabular}

Para cada experimento, médias seguidas por mesma letra maíuscula na linha e por mesma letra minúscula na coluna não diferem estatisticamente, entre si, pelo teste Tukey $(P>0,05)$. 
Tabela 9. Teste de envelhecimento artificial: dados (\%) obtidos após a aplicação dos tratamentos.

\begin{tabular}{clcccc}
\hline \multirow{2}{*}{ Experimentos } & \multicolumn{1}{c}{ Etapas de inoculação } & \multicolumn{3}{c}{ Danificações } \\
\cline { 3 - 6 } 1 & Assepsia & $98 \mathrm{Aa}$ & $97 \mathrm{Aa}$ & $23 \mathrm{Bb}$ & $14 \mathrm{Cb}$ \\
& Assepsia + BDA & $88 \mathrm{Ac}$ & $76 \mathrm{Bc}$ & $10 \mathrm{Dc}$ & $16 \mathrm{Cb}$ \\
& Assepsia + BDA + Aspergillus sp. & $95 \mathrm{Ab}$ & $81 \mathrm{Bb}$ & $36 \mathrm{Ca}$ & $20 \mathrm{Da}$ \\
\hline \multirow{3}{*}{2} & Assepsia & $97 \mathrm{Ba}$ & $99 \mathrm{Aa}$ & $25 \mathrm{Ca}$ & $17 \mathrm{Db}$ \\
& Assepsia + BDA & $87 \mathrm{Ac}$ & $77 \mathrm{Bc}$ & $12 \mathrm{Db}$ & $18 \mathrm{Cb}$ \\
& Assepsia + BDA + Penicillium sp. & $94 \mathrm{Ab}$ & $90 \mathrm{Bb}$ & $27 \mathrm{Da}$ & $38 \mathrm{Ca}$ \\
\hline \multirow{3}{*}{3} & Assepsia & $99 \mathrm{Aa}$ & $98 \mathrm{Aa}$ & $27 \mathrm{Ba}$ & $19 \mathrm{Cb}$ \\
& Assepsia + BDA & $97 \mathrm{Ab}$ & $98 \mathrm{Aa}$ & $16 \mathrm{Bb}$ & $15 \mathrm{Bc}$ \\
& Assepsia + BDA + Fusarium moniliforme & $96 \mathrm{Ac}$ & $93 \mathrm{Bb}$ & $4 \mathrm{Dc}$ & $21 \mathrm{Ca}$ \\
\hline
\end{tabular}

Para cada experimento, médias seguidas por mesma letra maíuscula na linha e por mesma letra minúscula na coluna não diferem estatisticamente, entre si, pelo teste Tukey $(P>0,05)$. 
Tabela 10. Teste de frio: dados (\%) obtidos após a aplicação dos tratamentos.

\begin{tabular}{cllcccc}
\hline \multirow{2}{*}{ Experimentos } & \multicolumn{3}{c}{ Danificações } \\
\cline { 3 - 6 } & & Eo & D1 & $\mathrm{D}_{2}$ & $\mathrm{D}_{3}$ \\
\hline \multirow{2}{*}{1} & Assepsia & $95 \mathrm{Aa}$ & $71 \mathrm{Bc}$ & $71 \mathrm{Ba}$ & $68 \mathrm{Bb}$ \\
& Assepsia + BDA & $95 \mathrm{Aa}$ & $90 \mathrm{Ba}$ & $67 \mathrm{Db}$ & $76 \mathrm{Ca}$ \\
& Assepsia + BDA + Aspergillus sp. & $92 \mathrm{Ab}$ & $87 \mathrm{Bb}$ & $55 \mathrm{Cc}$ & $56 \mathrm{Cc}$ \\
\hline \multirow{2}{*}{2} & Assepsia & $98 \mathrm{Aa}$ & $77 \mathrm{Bc}$ & $76 \mathrm{Ba}$ & $71 \mathrm{Cb}$ \\
& Assepsia + BDA & $97 \mathrm{Aa}$ & $86 \mathrm{Bb}$ & $66 \mathrm{Db}$ & $74 \mathrm{Ca}$ \\
& Assepsia + BDA + Penicillium sp. & $93 \mathrm{Bb}$ & $97 \mathrm{Aa}$ & $56 \mathrm{Dc}$ & $77 \mathrm{Ca}$ \\
\hline \multirow{2}{*}{3} & Assepsia & $99 \mathrm{Aa}$ & $77 \mathrm{Bc}$ & $77 \mathrm{Ba}$ & $78 \mathrm{Ba}$ \\
& Assepsia+ BDA & $97 \mathrm{Ab}$ & $88 \mathrm{Bb}$ & $70 \mathrm{Db}$ & $75 \mathrm{Ca}$ \\
& Assepsia + BDA + Fusarium moniforme & $95 \mathrm{Ac}$ & $92 \mathrm{Ba}$ & $28 \mathrm{Dc}$ & $67 \mathrm{Cb}$ \\
\hline
\end{tabular}

Para cada experimento, médias seguidas por mesma letra maíuscula na linha e por mesma letra minúscula na coluna não diferem estatisticamente, entre si, pelo teste Tukey $(P>0,05)$. 
Tabela 11. Teste de comprimento da plântula: dados (mm) obtidos após a aplicação dos tratamentos.

\begin{tabular}{clrrrr}
\hline \multirow{2}{*}{ Experimentos } & \multicolumn{3}{c}{ Danificações } \\
\cline { 3 - 5 } 1 & & Do & D1 & $\mathrm{D}_{2}$ & $\mathrm{D}_{3}$ \\
\hline \multirow{2}{*}{1} & Assepsia & $46 \mathrm{Aa}$ & $45 \mathrm{Aa}$ & $21 \mathrm{Ba}$ & $18 \mathrm{Ca}$ \\
& Assepsia + BDA & $45 \mathrm{Aab}$ & $45 \mathrm{Aa}$ & $7 \mathrm{Bb}$ & $5 \mathrm{Cc}$ \\
& Assepsia + BDA + Aspergillus sp. & $43 \mathrm{Ab}$ & $32 \mathrm{Bb}$ & $9 \mathrm{Cb}$ & $7 \mathrm{Db}$ \\
\hline \multirow{2}{*}{2} & Assepsia & $47 \mathrm{Aa}$ & $51 \mathrm{Aa}$ & $25 \mathrm{Ba}$ & $22 \mathrm{Ba}$ \\
& Assepsia + BDA & $47 \mathrm{Aa}$ & $46 \mathrm{Ab}$ & $7 \mathrm{Bc}$ & $8 \mathrm{Bb}$ \\
& Assepsia + BDA + Penicillium sp. & $39 \mathrm{Ab}$ & $26 \mathrm{Bc}$ & $14 \mathrm{Cb}$ & $7 \mathrm{Db}$ \\
\hline \multirow{2}{*}{3} & Assepsia & $49 \mathrm{Aa}$ & $48 \mathrm{Aa}$ & $27 \mathrm{Ba}$ & $28 \mathrm{Ba}$ \\
& Assepsia + BDA & $46 \mathrm{Bb}$ & $48 \mathrm{Aa}$ & $8 \mathrm{Cc}$ & $9 \mathrm{Cb}$ \\
& Assepsia + BDA + Fusarium moniliforme & $45 \mathrm{Ab}$ & $17 \mathrm{Bb}$ & $14 \mathrm{Cb}$ & $4 \mathrm{Dc}$ \\
\hline
\end{tabular}

Para cada experimento, médias seguidas por mesma letra maíuscula na linha e por mesma letra minúscula na coluna não diferem estatisticamente, entre si, pelo teste Tukey $(P>0,05)$. 
Tabela 12. Teste de emergência das plântulas: dados (\%) obtidos após a aplicação dos tratamentos.

\begin{tabular}{|c|c|c|c|c|c|}
\hline \multirow[b]{2}{*}{ Experimentos } & \multirow[b]{2}{*}{ Etapas de inoculação } & \multicolumn{3}{|c|}{ Danificações } & \multirow[b]{2}{*}{ D3 } \\
\hline & & Do & $\mathrm{D}_{1}$ & $\mathrm{D} 2$ & \\
\hline \multirow{3}{*}{1} & Assepia & 97Aa & 96Aa & $71 \mathrm{Bb}$ & $70 \mathrm{Bb}$ \\
\hline & Assepsia + BDA & $97 \mathrm{Aa}$ & $94 \mathrm{Bb}$ & $76 \mathrm{Ca}$ & $77 \mathrm{Ca}$ \\
\hline & Assepsia + BDA + Aspergillus sp. & $97 \mathrm{Aa}$ & $68 \mathrm{BCC}$ & $65 \mathrm{Cc}$ & $70 \mathrm{Bb}$ \\
\hline \multirow{3}{*}{2} & Assepsia & $98 \mathrm{Ba}$ & $99 \mathrm{Aa}$ & $76 \mathrm{Ca}$ & $71 \mathrm{Db}$ \\
\hline & Assepsia + BDA & 97Aab & $97 \mathrm{Ab}$ & $77 \mathrm{Ba}$ & $74 \mathrm{Bb}$ \\
\hline & Assepsia + BDA + Penicillium sp. & $96 \mathrm{Ab}$ & $96 \mathrm{Ab}$ & $65 \mathrm{Cb}$ & $88 \mathrm{Ba}$ \\
\hline \multirow{3}{*}{3} & Assepsia & $100 \mathrm{Aa}$ & $98 \mathrm{Ba}$ & $77 \mathrm{Ca}$ & $77 \mathrm{Ca}$ \\
\hline & Assepsia + BDA & $97 \mathrm{Ab}$ & $97 \mathrm{Aa}$ & $77 \mathrm{Ba}$ & 75Ba \\
\hline & Assepsia + BDA + Fusarium moniliforme & $97 \mathrm{Ab}$ & $94 \mathrm{Bb}$ & $34 \mathrm{Db}$ & $73 \mathrm{Ca}$ \\
\hline
\end{tabular}

Para cada experimento, médias seguidas por mesma letra maíuscula na linha e por mesma letra minúscula na coluna não diferem estatisticamente, entre si, pelo teste Tukey $(P>0,05)$. 


\section{CONCLUSÕES}

- As danificações em sementes de milho, particularmente quando Aspergillus sp. e Fusarium moniliforme acham-se presentes, promovem prejuízos qualitativos progressivos à medida que se aproximam do embrião.

- Quando comparadas entre si, as interferências negativas de Aspergillus sp. e de Fusarium moniliforme são mais evidentes do que as de Penicilium sp. 


\section{REFERÊNCIAS BIBLIOGRÁFICAS}

BEWLEY, J. D.; BLACK, M. Seeds: physiology of development and germination. New York: Plenum Press, 1985. 367p.

BRASIL. Ministério da Agricultura, do Abastecimento e da Reforma Agrária. Departamento Nacional de Produção Vegetal - Divisão de Sementes e Mudas. Regras para Análise de Sementes. Brasília, 1992. 365p.

BRASS, R. W.; MARLEY, S. J. Roller sheller: low damage corn shelling cylinder. Transactions of the America Society of Agricultural Engineers,v.16,n.1,1973. p. 64-66.

BUNCH, H. D. Mechanical injury in seeds: its causes and efects. In: Annual Convention South Carolina Seedsmen's Association, Clenson, South Carolina, p. 1-8, 1960.

CARVALHO, N. M. DE; NAKAGAWA, J. Sementes: ciência, tecnologia e produção. Campinas: SP, Fundação CARGILL, 1983. 429p.

COPELAND, L. O. How seed damage affects germination. Crops and Soils Magazine, Madison, v. 24, n. 9. 1972. p. 9-12. 
CRAIG, W. F. Production of hybrid corn seed. In: Sprague, G. F. , (Ed.) Corn and corn improvement. Wasgington, American Society of Agronomy. $p$. 671-719, 1977.

DALE, J. L. Testing fungicides for corn seed treatment. Ark. Farm. Res. , Fayetteville, v. 8, n. 3, 5p., 1959.

DELOUCHE, J. C.; ANDREWS, C. H. Tests show how injury lowers quality of seed. Seed World, Chicago, v. 95, n. 6, p.10, 1964.

DHINGRA, O. D.; MUCHOVEJ, J. J.; CRUZ FILHO, J. Tratamento de sementes: controle de patógenos. Viçosa: Imprensa Universitária. 1980. $121 \mathrm{p}$.

FAGUNDES, S. R. F. Como predizer a qualidade de um lote de sementes. Sementes, Brasília, v. 10, n. 6, p. 14-18, 1985.

FILGUEIRAS, T. S. Seed vigor and productivity. Pesquisa Agropecuária Brasileira, v. 16, n. 6, p. 851-854, 1981.

FINCH, E. O.; COELHO, A. M.; BRANDINI, A. Colheita de milho. Informe Agropecuário, v. 6, n. 72, p. 61-66, Dez. 1980.

GONÇALVES, C. A. R. Efeitos de métodos de colheita e debulha de sementes sobre a germinação e produção de milho (Zea mays L.) Piracicaba, 1981. 122p. (Mestrado - Escola Superior de Agricultura "Luiz de Queiróz", Universidade de São Paulo). 
GOODSELL, S. F. What damages seed corn? Cold test detects problem. Crops \& Soils Magazine, v.16, n. 7, p. 21, Abri./ Mai. 1964.

HOPPE, P. E. Seed treatment with mercury dusts injurious to corn with mechanical injuries near embryo. Phytopathology, v. 38, p. 82, 1948.

HURD, A. M. Seed-coat injury and viabbility of seeds of wheat and barley as factors susceptibility to molde and fungicides. Journal Agricultural Research, v. 31, n.1, p.119-120, 1921.

LÓPEZ, L. C.; CHRISTENSEN, C. M. Effect of moisture content and temperature on invasion of stored corn by Aspergillus flavus. Phytopathology, v. 57, p. 588-590, 1967.

LUCCA FILHO, O. A.. Importância da sanidade na produção de sementes de alta qualidade. Revista Brasileira de Sementes, v. 7, n. 1, p. 113-123, 1985.

KOELHER, B. Pathologie significance of seed coat injury in dent corn. Phytopathology, v.25, p.24, 1935.

KRZYZANOWSKI, F. C.; FRANÇA NETO, J. B.; HENNING, A. A. Relato dos testes de vigor disponíveis para grandes culturas. In: Informativo ABRATES. v.1, n.2. p. 15-50, 1991.

MACHADO, J. C.; MARTINS, L. P. S. Informativo ABRATES. Resumo 165, vol.9, n.1-2, Julho/Agosto, 1999. 
MARCOS FILHO, J. Germinação de sementes. In: Semana de Atualização em produção de sementes, 1., 1986, Piracicaba. Campinas: Fundação Cargill, 1986. p.11-39.

MARCOS FILHO, J.; CICERO, S.M.; Toledo, F. F. Manual de análise de sementes. Piracicaba: ESALQ, 1985. 112p. (Mimeografado).

MCKEEN, W. E.; MACDONALD, B. Leakage, infection and emergence of injured corn seed. Phytopathology, v.66, p.928-930, 1976.

MEYERS, M. T. The influence of broken pericarp on the germination and yield of corn. Journal of the American Society of Agronomy, v.16, n. 8, p. 540550, Ago. 1924.

MOORE, R. P. Effects of Mechanical injuries on viability. In: ROBERTS, E. H. (Ed) Viability of seeds. London: Chapman \& Hall Ltd. e Siracure University Press., 1974. p.94-113.

NAKAGAWA, J. Testes de vigor baseados na avaliação das plântulas. In: Vieira, R. D.; Carvalho, N. M. , (Ed.). Testes de vigor em sementes. Jaboticabal: FUNEP, 1994, p. 59-65.

NEERGAARD, P. Seed Pathology. London: Macmillan Press, 1979. v. 1 , 839p.

NIJENSTEIN, J. H. Effects of some factors influencing cold test germination of maize. Seed Science \& technology, v. 14, n. 2, p. 313-326, 1986. 
PEREIRA, O. A. A patologia de sementes no contexto da indústria brasileira de sementes. In: SIMPÓSIO BRASILEIRO DE PATOLOGIA DE SEMENTES, 1., Piracicaba, 1984. Anais. Piracicaba: ABRATES, 1984. p. 30-32.

POLLOCK, B. M.; ROOS, E. E. Seeds and deedling vigor. In: KOZLOWSKY, T. T. ED. Seed Biology. New York, Academic Press, v.1, p. 313-387, 1972.

POPINIGIS, F. Fisiologia da semente. Brasília: Ministério da Agricultura, AGIPLAN, 1977. 289p.

RICHARDISON, M. J. Suplement 1 to annotated list of seed borne diseases. 3.ed Zurich: ISTA, 1981. 78p.

ROCHA, F. E.; CORDEIRO, C. M. T.; GIORDANO, L. DE B.; CUNHA, J. M. Danos mecânicos na colheita de sementes de ervilha. Pesquisa Agropecuária Brasileira, v.19, n. 9, p.1117-1121, Set., 1984.

SATO, O. Efeitos da seleção de espigas e da debulha na qualidade física e fisiológica das sementes de milho (Zea mays L.). Piracicaba, 1974. 49p (Tese de Mestrado - Escola Superior de Agricultura "Luiz de Queiroz", Universidade de São Paulo).

SCHWARTZ, H. F. Diversos patógenos fúngicos. In: SCHWARTZ, H. F.; GÁLVEZ G. E. (Ed.). Problemas de produccion del frijol: enfermedades, insectos, limitaciones edáficas y climáticas de Phaseolus vulgaris. Cali: CIAT, 1980. cap. 8, p. 127-151. 
SILVA, W. R.; CHAMMA, H. M. C. P.; NOVEMBRE, A. D L. C.; MORAES, M. H. D. Avaliação do desempenho de sementes de milho submetidas à remoção parcial do endosperma e do pericarpo. Scientia Agricola, v.51, n.1, p.138152, Jan./Abr.. 1994.

SOAVE, J.; WETZEL, M. V. S. ( Ed.) Patologia de sementes. Campinas: Fundação Cargill, 1987. 480p.

TANAKA, M. A. S.; MACHADO, J. C. Patologia de sementes. Informe Agropecuário, v. 11, n. 122, p. 40-46, 1985.

TANAKA, M. A. S.; CORREAA, M. U. Influência de Aspergillus e Penicillium no armazenamento de sementes de feijão (Phaseolus vulgaris L.). Fitopatologia Brasileira, v. 11, n. 122, p. 40-46, 1985.

TATUM, L. A.; ZUBER, M. S. Germination of maize underadverse conditions. Journal of the American Society of Agronomy, v. 35, n.1, p. 48-49, 1943.

TOLEDO, F. F.; MARCOS FILHO, J. Manual das Sementes: Tecnolgia da Produção. São Paulo: Editora Agronômica Ceres, 1977. 224p.

WORTMAN, L. S.; RINKE, E. H. Seed corn injury at various stages of processing and its effect upon cold test performance. Agronomy Journal, v.43, n.7, p.229-305, 1951.

WU, W-S.; CHENG, K-C. Relationships between seed health, seed vigour and the performance of sorghum in the field. Seed Science \& Technology, $v$. 18, p. 713-719, 1990. 
ZONTA, E. P. ; MACHADO, A. A. Sistema de Análise Estatística para Microcomputadores. SANEST: Pelotas, 1984. 